\title{
A PRELIMINARY CROSS-SECTIONAL ASSESSMENT ON EXCLUSIVE BREASTFEEDING AMONG WOMEN ATTENDING A POSTNATAL CLINIC AT THE HOLY FAMILY HOSPITAL, TECHIMAN, GHANA
}

Edward

AGYARKO $^{1+}$

Akua Serwaa

BONSU $^{2}$

Ato Kwamena TETTEH $^{s}$

\author{
${ }^{\prime} M S c$., Lecturer, Department of Community Medicine and Health, Anglican \\ University College of Technology, Nkoranza, Ghana. \\ Email:edward.agyarko@angutech.edu.gh Tel: +233243119760 \\ ${ }^{2} B S c$. Community Medicine and Health, Department of Community Medicine \\ and Health, Anglican University College of Technology, Nkoranza, Ghana. \\ Email:serwaa.precious@gmail.com Tel: +233545050582 \\ ${ }^{s}$ MPhil., MPH, Medical Laboratory Scientist, Laboratory Department, \\ Metropolitan Hospital, P. O. Box 174, Cape Coast, Ghana. \\ Email:aktetteh@outlook.com Tel:+233244762196
}

ABSTRACT

\section{Article History}

Received: 9 July 2021

Revised: 16 August 2021 Accepted: 3 September 2021 Published: 20 September 2021

\section{Keywords \\ Infants \\ Breastfeeding \\ Exclusive \\ Ghana \\ Underweight \\ Education.}

\begin{abstract}
Exclusive breastfeeding (EBF) for the first six months of life has remained low in Ghana, despite strong evidence of benefits to babies/infants that supports the practice. This study is a preliminary assessment of the adherence to EBF among mothers attending the postnatal clinic. Methods: The study was cross-sectional, involving 85 breastfeeding mothers who attended the postnatal clinic at the Holy Family Hospital, Techiman. A structured questionnaire was used to collect data on socio-demographic information and adherence to EBF. A total of 85 mothers and their babies (50 females and 35 males) participated in the study. Out of this total, $45.9 \%(39 / 85)$ were exclusively breastfed, while $54.1 \%(46 / 85)$ were non-exclusively breastfed. About $17.6 \%$ of the mothers with Junior High School (JHS) education exclusively breastfed their babies compared to those with Senior High School (SHS) (15.3\%) and tertiary (12.9\%) $(\mathrm{p}>0.05)$. Babies who were not exclusively breastfed were $12.9 \%(11 / 85), 17.6 \%$ $(15 / 85)$, and $23.5 \%(20 / 85)$ for mothers with JHS, SHS, and tertiary education respectively $(\mathrm{r}=0.182, \mathrm{p}=0.096)$. The distribution of weight classification among exclusive and non-exclusively breastfed babies was significantly different $\left(\chi^{2}=13.583\right.$, p 0.001). The findings of this study provide a preliminary assessment of adherence to EBF in Techiman, Ghana. Exclusive breastfeeding practices appear suboptimal. Education and working status of mothers negatively impact adherence on exclusive breastfeeding. Interventions emphasizing the continuous education of mothers could promote exclusive breastfeeding.
\end{abstract}

Contribution/Originality: This study documents a preliminary assessment of adherence to Exclusive Breastfeeding among women attending postnatal clinic at Holy Family Hospital in Techiman, Ghana.

\section{INTRODUCTION}

The importance of breastfeeding practices for the healthy growth and development of infants and young children has been presented in numerous policy documents [1]. Breastfeeding practices are categorized into two broad aspects: exclusive breastfeeding and complementary feeding [2]. Each of these practices has guidelines on how to appropriately practice them to yield the maximum outcome or good health of children. Mothers are encouraged to exclusively breastfeed their infants for the first six months of their lives [3, 4]. However, breastfeeding is much more than giving infants and young children breast milk but a complex adaptive process that bonds a mother and her child. During this process, physical, hormonal, biochemical, and psychological exchanges 
facilitate the transfer of needed essential nutrients between the mother and her child [5]. Reports show that good breastfeeding practices, especially exclusive breastfeeding (EBF), could prevent about $11.6 \%$ of the 6.9 million under-five deaths in developing countries [6]. After six months of exclusive breastfeeding, breastfeeding should be continued with added complementary feeds recommended by World Health Organization [7]. At this stage, it is required that infants receive nutritionally adequate complementary feed by introducing them gradually to family foods [1]. Research indicates that sometimes mothers are influenced negatively by significant others as to how to practice breastfeeding [8]. Other challenges include the belief that breast milk alone is not sufficient in meeting the nutritional needs of infants, short maternal leave period, socio-cultural pressure to introduce water and artificial feeds. While some mothers try to breastfeed exclusively, most perceive exclusive breastfeeding to be too difficult and tasking and resort to feeding their babies with infant formula [9]. Employed women were more likely not to practice exclusive breastfeeding compared to unemployed women due to the nature of their jobs [10, 11]. Also, some employers do not encourage working mothers' optimal exclusive breastfeeding practice after the maternity period because they think it will interfere with their daily work. So, when mothers get back to work, and there is no baby-friendly place or room where they can have their babies close by to breastfeed, it can be a big problem to breastfeed [12] exclusively.

Despite the benefits and efforts to promote breastfeeding, EBF is sub-optimally practiced in many developing countries, including Ghana. It is therefore essential that mothers are counselled, encouraged, and supported to initiate exclusive breastfeeding. Government, family members, and community health workers have various roles to play in the survival of newborns through uptake of exclusive breastfeeding [13] The focus of this study would highlight issues that impede exclusive breastfeeding practice.

\section{METHODS}

\subsection{Study Site}

The study was conducted at the Holy Family Hospital, Techiman, a Municipal Hospital, and offers a wide range of services. The hospital is part of the National Catholic Health Services (NCHS) and a member of the Christian Health Association of Ghana (CHAG). This hospital is located in the vibrant commercial town of Techiman $\left(7^{\circ} 35^{\prime} 30.7 " \mathrm{~N} 1^{\circ} 56^{\prime} 16.1 \mathrm{~W}\right)$. The facility provides general and specialist care and a major referral center to Techiman Municipality and beyond (Brong Ahafo Region). The hospital trains doctors and physician assistants by the Medical and Dental Council. In addition, the Ghana College of Physicians and Surgeons has designated the hospital for the training of residents in family medicine.

\subsection{Study Population}

The target population included mothers (15-35 years) with children aged 6 to 12 months at the Holy Family Hospital who visited the clinic for postnatal care services and various immunizations for their babies.

\subsection{Study Design and Sample Size}

A cross-sectional descriptive study was used. In addition, a questionnaire consisting of both close and openended questions was used. The open-ended questions were included to gain an understanding of why mothers gave a specific answer. The study sampled 85 women who attended the postnatal clinic at Holy Family Hospital.

\subsection{Ethical Consideration}

The hospital granted authorization to carry out this study for information and educational purposes. Participants' consent was received, and their identity was concealed by providing unique identifiers. In addition, participants were informed of their right to withdraw from participating in the study. 


\subsection{Data Analysis}

The IBM ${ }^{\circledR}$ Statistical Package for Social Science (SPSS) (Version 27) was used. The Data was analyzed according to socio-demographic characteristics and adherence to exclusive breastfeeding. The correlation coefficient was estimated to determine the association between breastfeeding and the level of education of mothers. The Chisquare test was used to determine the difference between the percentage of babies with normal weight, underweight, and overweight. Test of statistical significance was determined at $\mathrm{p}<0.05$.

\section{RESULTS}

\subsection{Assessing Practices That Support Exclusive Breastfeeding}

Figure 1 below shows the percentage of mothers who exclusively breastfed. A total of 85 mothers with children aged 6 to 12 months (50 females and 35 males) were involved in this study. Mothers who exclusively breastfed their babies constituted $45.9 \%$ (39/85), while $54.1 \%$ (46/85) did not adhere to exclusive breastfeeding.

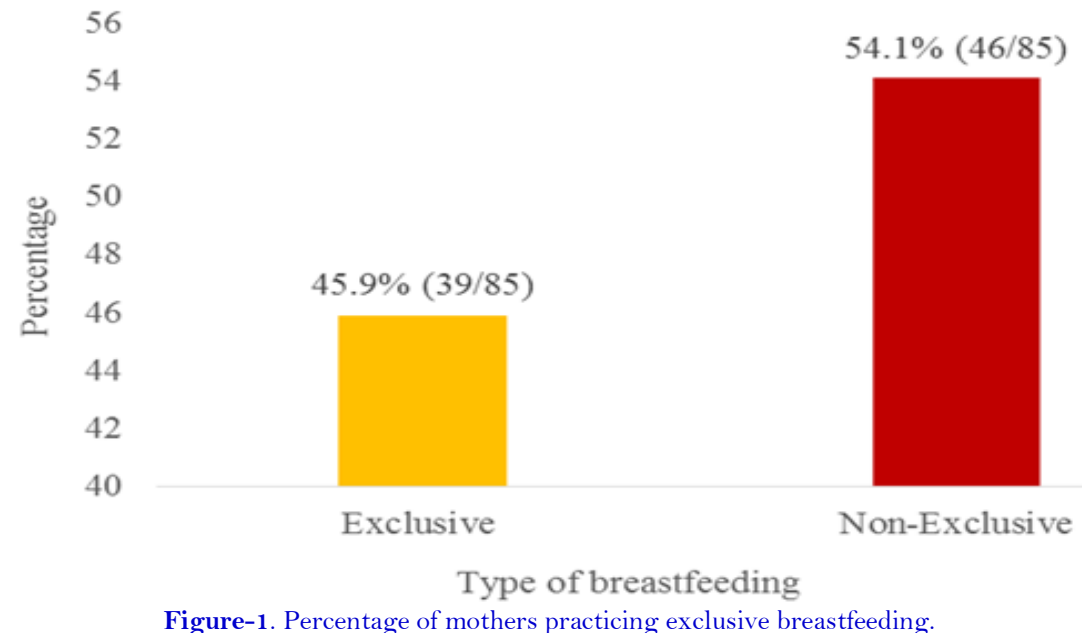

\subsection{Association between the Level of Education and the Practice of EBF}

Table 1 below shows the effect of education on the practice of EBF. Of the total,17.6\% (15/85 with Junior High School (JHS) education exclusively breastfed as compared to those with Senior High School education, $15.3 \%$ (13/85), and tertiary education 12.9\%(11/85). As well, 12.9\% (11/85) with JHS education did not exclusively breastfeed, compared to $17.6 \%(15 / 85)$ with SHS education and $23.5 \%(20 / 85)$ with tertiary education $(\mathrm{r}=0.182$, $\mathrm{p}$ $=0.096)$.

Table-1. Effect of education on the practice of Exclusive Breastfeeding.

\begin{tabular}{c|c|c|c|c}
\hline \multirow{2}{*}{ EBF status } & \multicolumn{3}{|c|}{ Level of education n (\%) } & \multirow{2}{*}{ Total } \\
\cline { 2 - 4 } & JHS & SHS & Tertiary & 39 \\
\hline Exclusive & $15(17.6)$ & $13(15.3)$ & $11(12.9)$ & 46 \\
\hline Non-exclusive & $11(12.9)$ & $15(17.6)$ & $20(23.5)$ & 85 \\
\hline Total & 26 & 28 & 31 &
\end{tabular}

\subsection{Effect of Working Status on the Practice of Exclusive Breastfeeding}

In line with the main objective, respondents were asked to state if they could practice the recommended exclusive breastfeeding according to World Health Organisation standard with their breastfeeding with the nature of their work. From Table 2, 21.2\% of women were employed as professionals, 18.8\% (16/85) unemployed, and $14.1 \%(12 / 85)$ self-employed mothers could not practice exclusive breastfeeding. On the other hand, 27.1\% (23/85) 
unemployed mothers, 10.6\% (9/85) self-employed, and 8.2\% (7/85) practiced exclusive breastfeeding $(\mathrm{r}=0.167, \mathrm{p}=$ $0.127)$.

Table-2. Effect of working status on the practice of exclusive breastfeeding.

\begin{tabular}{c|c|c|c|c}
\hline \multirow{2}{*}{ EBF Status } & \multicolumn{3}{|c|}{ Employment Status } & \multirow{2}{*}{ Total } \\
\cline { 2 - 4 } & Unemployed & Professional & Self-employed & 39 \\
\hline Exclusive & $23(27.1)$ & $7(8.2)$ & $9(10.6)$ & 46 \\
\hline Non-exclusive & $16(18.8)$ & $18(21.2)$ & $12(14.1)$ & 85 \\
\hline Total & 39 & 25 & 21 & \\
\hline
\end{tabular}

Figure 2 below shows the weight classification of exclusive and non-exclusive breastfed infants. Of the total number of babies weighed, 32.9\% (28/85) were normal weight, 38.8\% (33/85) were underweight, while $28.2 \%$ $(24 / 85)$ were overweight. As well, $23.5 \%(20 / 85)$ of exclusively breastfed babies had normal weight, 9.4\% (8/85) underweight, and $12.9 \%(11 / 85)$ were overweight $\left(\chi^{2}=13.583, \mathrm{p} 0.001\right)$. With regards to babies who were not exclusively breastfed, 9.4\% (8/85) were normal weight, $29.4 \%(25 / 85)$ were underweight, while $15.3 \%(13 / 85)$ were overweight.

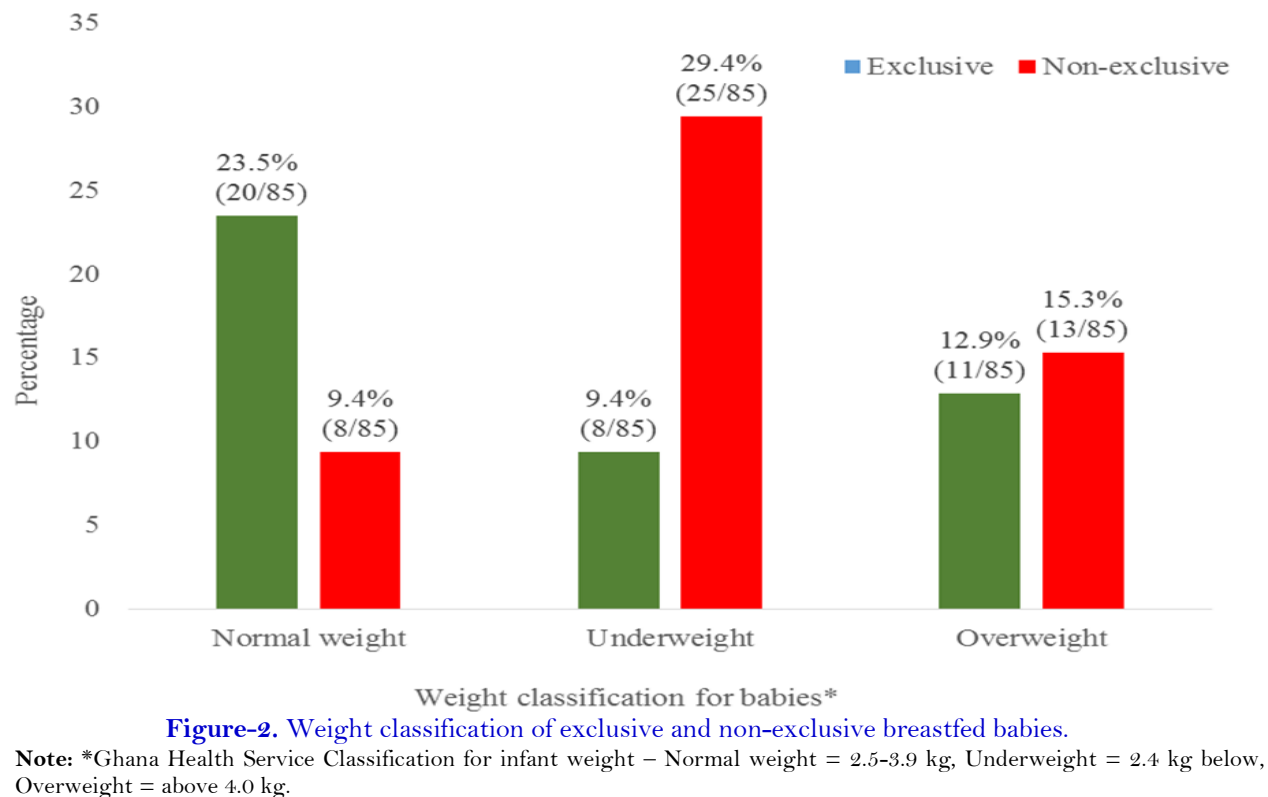

\section{DISCUSSION}

The mother's level of education was considered to be a barrier to exclusive breastfeeding. Although research has established a positive correlation between higher education and exclusive breastfeeding $[14,15]$ this study found that most mothers that exclusively breastfed their babies were those with low education. Breastfeeding status decreases with the mother's educational level [16, 17]. Also, mothers with no or primary education exclusively breastfeed than mothers with higher education [18, 19]. Some surveys have established that employment status and work environments may adversely impact the duration of breastfeeding [20, 21]. For instance, in these studies, most mothers who exclusively breastfed their babies were unemployed compared to those with professional work or are self-employed. According to Aryeetey and Goh [3], mothers in business and professional work are more likely not to maintain exclusive breastfeeding because of their busy schedules [22]. The practice of EBF is supposed to be uninterrupted for six months and is usually seen as time-consuming by working mothers. Most mothers have challenges coping with practicing EBF because of work demands and the unavailability of places designated for breastfeeding at their workplace. Another study reported that countries with guaranteed breastfeeding breaks at work had $71 \%$ of their working mothers practicing exclusive breastfeeding. In comparison, only $4 \%$ of working 
mothers exclusively breastfed in countries with unpaid guaranteed breaks [23]. In this current study, the lack of $\mathrm{EBF}$ reflected the infant's current weight status, reflecting the nutritional status. Our data show a significantly higher number, 20 out of 39, exclusively breastfed babies having normal weight. Of the 46 babies who were not exclusively breastfed, 25 were underweight. In our view, this outcome could be due to the early introduction of complementary foods, which may predispose the child to waste and, eventually, stunting. A similar study done in India among tea garden workers of Assam reported low birth weight among exclusively breastfed and nonexclusively breastfed infants as underweight, wasting, and stunting [24]. We are uncertain what might have influenced underweight and overweight in exclusively breastfed babies. Likewise, there is the need to investigate further why babies who are not exclusively breastfed could have normal weight or overweight status.

\section{CONCLUSION/IMPLICATIONS FOR PRACTICE}

Exclusive breastfeeding practices for our study population are sub-optimal. The education and working status of mothers affect the adherence to exclusive breastfeeding of babies. Even though initial breastfeeding is common in developing worlds, exclusive breastfeeding for six months is regularly not normal. Interventions emphasizing practical education should therefore be targeted to help promote exclusive breastfeeding.

Funding: This study received no specific financial support.

Competing Interests: The authors declare that they have no competing interests.

Acknowledgement: Authors are grateful to all staffs at the ante- and postnatal clinic of the

Holy Family Hospital, Techiman, Ghana.

\section{REFERENCES}

[1] A. Aliyu and M. Shehu, "Knowledge attitude and practice of exclusive breastfeeding among multigravid women attending antenatal clinic in Aminu Kano University Teaching Hospital," IOSR Journal of Nursing and Health Science, vol. 5, pp. 59-74, 2016.

S. Arora, C. McJunkin, J. Wehrer, and P. Kuhn, "Major factors influencing breastfeeding rates: Mother's perception of father's attitude and milk supply," Pediatrics, vol. 106, pp. e67-e67, 2000.Available at: https://doi.org/10.1542/peds.106.5.e67.

[3] R. Aryeetey and Y. Goh, "Duration of exclusive breastfeeding and subsequent child feeding adequacy," Ghana Medical Journal, vol. 47, pp. 24-29, 2013.

[4] M. S. Bhandari, P. Manandhar, and D. Tamrakar, "Practice of breastfeeding and its barriers among women working in tertiary level hospitals," Journal of Nepal Medical Association, vol. 57, pp. 8-13, 2019.Available at: https://doi.org/10.31729/jnma.4035.

[5] L. Elyas, A. Mekasha, A. Admasie, and E. Assefa, "Exclusive breastfeeding practice and associated factors among mothers attending private pediatric and child clinics, Addis Ababa, Ethiopia: A Cross-Sectional Study," International Journal of Pediatrics, vol. 2017, pp. 1-9, 2017.Available at: https://doi.org/10.1155/2017/8546192.

[6] N. Essien and P. Samson-Akpan, "Factors influencing the practice of exclusive breastfeeding among women in Ikot Omin, Calabar, Nigeria," Mary Slessor Journal of Medicine, vol. 12, pp. 51-63, 2013.

[7] A. Ezeogu, "Water is the greatest barrier to exclusive breastfeeding; Retrieved from: https://www.vanguardngr.com/2017/08/water-greatest-barrier-exclusive-breastfeeding-ada-ezeogu-unicefnutritionist/ [Accessed 2021 May 25]. ," 2017.

[8] Ghana - Multiple Indicator Cluster Survey, "Multiple indicator cluster survey 2011. Retrieved from: https://microdata.worldbank.org/index.php/catalog/2046. [Accessed 2021 May 27]," 2011.

[9] J. Heymann, A. Raub, and A. Earle, "Breastfeeding policy: A globally comparative analysis," Bulletin of the World Health Organization, vol. 91, pp. 398-406, 2013.Available at: https://doi.org/10.2471/blt.12.109363. 
[10] S. Horton, T. Sanghvi, M. Phillips, J. Fiedler, R. Perez-Escamilla, C. Lutter, A. Rivera, and A. M. SEGALL-CORREA, "Breastfeeding promotion and priority setting in health," Health Policy and Planning, vol. 11, pp. 156-168, 1996.

[11] M. Khassawneh, Y. Khader, Z. Amarin, and A. Alkafajei, "Knowledge, attitude and practice of breastfeeding in the north of Jordan: A cross-sectional study," International Breastfeeding Journal, vol. 1, pp. 1-6, 2006.Available at: https://doi.org/10.1186/1746-4358-1-17.

[12] C. Lutter, "Complementary feeding: Biological, behavioural and contextual rational. Retrieved from: https://www.who.int/elena/titles/bbc/complementary_feeding/en/. [Accessed May 25, 2021]," 2021.

[13] G. Medhi and J. Mahanta, "Breastfeeding, weaning practices and nutritional status of infants of tea garden workers of Assam," Indian Pediatr, vol. 41, pp. 1277-9, 2004.

[14] A. K. Manyeh, D. E. Akpakli, V. Kukula, R. A. Ekey, S. Narh-Bana, A. Adjei, and M. Gyapong, "Socio-demographic determinants of skilled birth attendant at delivery in rural southern Ghana," BMC Research Notes, vol. 10, pp. 1-7, 2017.Available at: https://doi.org/10.1186/s13104-017-2591-z.

[15] A. d. 1. Mora, D. W. Russell, C. I. Dungy, M. Losch, and L. Dusdieker, "The Iowa infant feeding attitude scale: Analysis of reliability and validity," Journal of Applied Social Psychology, vol. 29, pp. 2362-2380, 1999.

[16] J. Nkrumah, "Maternal work and exclusive breastfeeding practice: A community based cross-sectional study in Efutu Municipal, Ghana," International Breastfeeding Journal, vol. 12, pp. 1-9, 2016.Available at: https://doi.org/10.1186/s 13006-017-0100-6.

[17] A. Nwachukwu and A. Nwachukwu, "Common factors responsible for less than six months period of exclusive breastfeeding among women in Nigeria," Journal-International Council for Health Physical Education Recreation Sport and Dance, vol. 43, pp. 30-35, 2007.

[18] L. Olagunju, "The importance of exlusive breastfeeding; Retrieved from: https://www.healthynewbornnetwork.org/blog/the-importance-of-exclusive-breastfeeding/_ [Accessed 2021 May 27]." 2012.

[19] T. N. Raju, "Breastfeeding is a dynamic biological process—not simply a meal at the breast," Breastfeeding Medicine, vol. 6, pp. 257-259, 2011.Available at: https://doi.org/10.1089/bfm.2011.0081.

[20] S. Tiwari, K. Bharadva, B. Yadav, S. Malik, P. Gangal, C. Banapurmath, Z. Zaka-Ur-Rab, U. Deshmukh, and R. Agrawal, "Infant and young child feeding guidelines, 2016," Indian Pediatrics, vol. 53, pp. 703-713, 2016.

[21] S. Valizadeh, M. Hosseinzadeh, E. Mohammadi, H. Hassankhani, M. M. Fooladi, and V. Schmied, "Addressing barriers to health: Experiences of breastfeeding mothers after returning to work," Nursing \& Health Sciences, vol. 19, pp. 105111, 2017.Available at: https://doi.org/10.1111/nhs.12324.

[22] K. M. Wood and K. Qureshi, "Facilitators and barriers for successful breastfeeding among migrant Chuukese mothers on Guam," SAGE Open Nursing, vol. 3, p. 2377960816688909, 2017.Available at: https://doi.org/10.1177/2377960816688909.

[23] World Health Organization, "The optimal duration of exclusive breastfeeding; Retrieved from: http://www.aleitamentomaterno.pt/images/artigos/UNICEF_duracao_AM_exclusivo.pdf. [Accessed 2021 May 25]," 2001.

[24] W. H. Organization., "Indicators for assessing breastfeeding practices: report of an informal meeting, 11-12 June , Geneva, Switzerland. Retrieved from: https://apps.who.int/iris/bitstream/handle/10665/62134/WHO_CDD_SER_91.14.pdf?sequence=1\&isAllowed=y. [Accessed 2021 May 30]," 1991.

Views and opinions expressed in this article are the views and opinions of the author(s), Journal of Nutrients shall not be responsible or answerable for any loss, damage or liability etc. caused in relation to/arising out of the use of the content. 